\title{
The Application and Thinking of Flexible Management in Enterprise Management
}

\author{
Lin Decai \\ Zijin Mining Group Co., Ltd.
}

\begin{abstract}
As a social group, the management of the enterprise is of great importance. And the new type of enterprise management model is an important driving force to maintain enterprises vitality and promote economy development. In the new period, enterprise management is faced with a new development situation due to new characteristics of enterprise employees, which raise new requirements for such a new type of enterprise management. This paper discusses and analyzes the inherent meaning of flexible management through the comparison between flexible management and traditional rigid management, and analyzes the new situation of enterprise development and the application of the guiding ideology of "people-oriented" in enterprise management based on the individual characteristics of employees, thus revealing the importance of flexible management model for enterprise management. At the same time, according to the idea of flexible management, it explores the practical implementation methods in enterprise management, which is helpful to promote the reform and development of new type of enterprise management in the new century.
\end{abstract}

Keywords-Enterprise management; Enterprise culture; Flexible management

\section{The Connotation Elements of FleXible Management}

At present, there are two kinds of management models in the new type of enterprise management, rigid management and flexible management. And enterprise managers often use both ways in employee management. The two parties are not hostile or quite distinct from each other, but enjoy a symbiotic state, in which they are inseparable, mutually tolerant and mutually complementary. It is helpful for us to better understand and grasp the flexible management and explore the effective path of the new type of enterprise management by defining the connotations of the two.

\section{A. The connotation of rigid management}

In enterprise management, rigid management, as its name suggests, refers to the management model that enterprise managers conduct daily training and management of employees, based on perfect $\&$ strict rules and regulations, and strict management organizations, through such management means as strict enforcement of orders and prohibitions and clear reward and punishment. In this model, the managers are in an absolutely strong position for the first impressions are strongest. Once at a time when the enterprise training and management model was relatively rigid and the personality of employees was not very prominent, this model had its own advantages and played an important role in China's enterprise management. Firstly, the rigid management model is simple and easy to practice. Only by using their own favorable positions to make reasonable and effective rules and regulations, and build an efficient and effective management team, managers can carry out staff management work in an orderly manner. Secondly, the traditional rigid management model is very effective. In rigid management, being in the dominant position, the managers make employees strictly and uniformly enforce their orders and prohibitions. Although it is kind of "brutal", it can effectively achieve the purpose of management.

However, with the development of society, the operating mode of enterprise is increasingly free and open, the personality of employees gradually becomes prominent and diverse, and the disadvantages of rigid management model expose as time goes by. The disadvantages are mainly in the following three aspects: First, the traditional rigid management model greatly limits employees' innovation ability and work enthusiasm. Therefore, they are lack of selfcontrol and participation awareness, and tend to fall into a passive state. Second, the flexibility of enterprise's organizations is greatly reduced in rigid management, thus affecting and even hindering the communication and coordination between organization and external environment, which will deprive employees of the possibility of access to work fun. Third, the rigid management model encourages employees' inertia, making them only seek to complete tasks in quantity, but lack of high quality standards. In essence, the rigid management model regulates the management of enterprises to some extent, but it forms a contradiction with the rich and varied inner emotional demand of employees. ${ }^{[1]}$ Based on this, managers have to seek new management methods and flexible management models, which give birth to flexible management model as time requires. In the new century, enterprise employees, with distinctive personality and strong autonomy, pursue a free and open working and living environment. In daily life and work, they follow self-pursuit and highlight personality. But rigid management model cannot fully adapt to the needs of enterprise management in the new era, for it rigidly adhering to the uniform, greatly suppressing employees' personality and limiting their autonomy.

\section{B. The connotation and characteristics of flexible management}

Facing the new features of office workers in the new century and the new situation in enterprise management, we must timely adjust the corresponding management model and 
explore new ways of enterprise management in the new period to further perfect enterprise management to improve its quality and level, and promote the stable operation and healthy development of enterprises. In view of the disadvantages of rigid management model, it is urgent to explore flexible management model.

\section{1) The concept of flexible management}

Flexible management is a management form that makes specific management objects consciously meet the manager's will with their own internal driving forces, by focusing on their psychological and behavioral characteristics and adopting encouraging, guiding and other moderate means to activate their enthusiasm and initiative.

Flexible management is a new management model, which is different from traditional rigid management with discipline restriction as its core. Its essence is humanized management and its core content is "people-oriented", thus resulting in the most prominent feature of flexible management, that is, the non-mandatory of flexible management mechanism. ${ }^{[2]}$ It can give full play to employees' subjective initiative, mobilize their enthusiasm and create an internal driving force in their mind, which promotes their behaviors in the flexible management mechanism to become self-conscious behaviors chronically and steadily. Thus, flexible management mechanism not only enjoys more potential, but also requires more investment and more difficult management model.

The flexible management in the new type of enterprise management is actually a humanized management model with the core content of "people-oriented". This model stimulates employee's motivation, initiative, and creativity by means of a variety of ways, such as spiritual encouragement, material incentives, emotional communication, exchange of views etc., or by the influence of managers' individual charisma on employee's actions and thinking, and guides them to make conscious behaviors by internal driving force, thus forming a long-term and stable self-management mechanism so as to achieve the purpose of sound management in the new type of enterprise management.

\section{2) The characteristics of flexible management model}

First of all, the "people-oriented" management philosophy is the most significant feature of flexible management mechanism. The flexible management mechanism embodies the people-oriented idea in the modern management philosophy. In the flexible management mechanism, all management activities should take "human management" as the core, respecting for human rights and giving full play to human initiative to mobilize people's enthusiasm and creativity and achieve free and overall development of people. The "people-oriented" feature of the flexible management model is first embodied in the democratization of the management process. Flexible management model changes the phenomenon that the managers have superior situation in the traditional rigid management model. It abandons the management approach in which the manager, as the core, does the unilateral constraint relying on their strong position. Flexible management is committed to creating a relaxed and free atmosphere and environment in which employees can get more free space, have more autonomy and arrange their study, life and work according to their personality and needs. This requires that managers should consider employees' special conditions, listen to their voices and opinions, and work out a reasonable and effective management program by fully considering their reasonable requirements based on the actual situation.

Secondly, the flexible management model takes incentive as its main management method. In the rigid management model, managers directly define employees' tasks or obligations, and explicitly tell them what they should do and should not do, mainly through formulating rules and regulations, and enforcing orders and prohibitions. But in the flexible management model, mainly through the method of guidance, managers help employees to set their own goals and action plans according to their own specific conditions, and mobilize their initiative and enthusiasm through the method of reward and punishment. On the way to their own goals, employees will gain managers' recognition when they make some progress or achievements. This will satisfy their selfesteem, gradually build up their self-confidence, and create a positive and healthy learning and working atmosphere and benign competition mechanism. Through establishing employees' self-esteem and self-confidence, effectively stimulating their enthusiasm and developing their selfmanagement ability, it transforms them from passively doing the tasks assigned by the managers to sincerely taking the initiative to put their own goals into practice and keep trying and exploring. ${ }^{[3]}$ Thus, they are encouraged to take their learning and work as self-conscious behaviors with strong, persistent motivation and high efficiency. Through selfeducation and self-management, they consciously plan their own behaviors, and gradually accomplish their short-term goals. In order to achieve their long-term goals, they will spontaneously continue to work hard and courageously strive for the first, so as to virtually meet the requirements and expectations of managers.

\section{THE NECESSITY TO IMPLEMENT FLEXIBLE MANAGEMENT IN THE NEW TYPE OF ENTERPRISE MANAGEMENT}

\section{A. Inherent requirements to establish a new, free and open enterprise culture and working atmosphere}

In traditional management model, enterprises take strict rules and regulations, management organizations, reward and punishment system as its main management method. Under this environment, the management system as well as the staff evaluation rule is rigid, and the personality of the enterprise members is ground to be mediocre, the overall cultural atmosphere of enterprises dull, monotonous and short of vitality and color. ${ }^{[4]}$ In the new period, the economic development is booming; our society changes with each passing day; scientific and technological advance is surging ahead. This has an increasingly important influence on enterprises. Therefore, in the face of the new period, the traditional enterprise management model must also make a change, and it is urgent to create a new working atmosphere and establish an open and independent enterprise culture that advocates science, pursues ideals, and absorbs anything and everything. 


\section{B. Requirements to practice the scientific management} concept of "people-oriented"

"People-oriented" is the inevitable requirement of the practice of scientific outlook on development. In 2003, Comrade Hu Jintao put forward the major strategic thinking of "Scientific Outlook on Development", which was written into the Party Constitution at the 17th CPC National Congress. Then, the 18th National Congress of the Communist Party of China formally listed it as the guiding ideology of the Party. The 18th CPC National Congress adopted the "Constitution of the Communist Party of China (Amendment)" and established the Scientific Outlook on Development with the MarxistLeninism, Mao Zedong Thought, Deng Xiaoping Theory and the important thinking of the "Three Represents" as guidelines for the action of the Communist Party of China. "Peopleoriented" is one of the important cores of Scientific Outlook on Development, and we should take the interests of the broad masses of the people as the starting point and the foothold of all work. The Political Bureau of the CPC Central Committee held a meeting on August 26, 2016, and the General Assembly considered and approved the planning outline of "Healthy China 2030". At the meeting, Secretary General Xi stressed that "Healthy China 2030" planning outline is the guideline that promotes the construction of health China in the next fifteen years and we should adhere to the development thought centered on the broad masses of the people and firmly establish and implement the five major development ideas.

Scientific Outlook on Development with the core of "People-oriented" has become the action guideline of the Communist Party of China and China's socialist construction, and the "people-oriented" value concept has also been included in the Chinese socialist core value system and become the core value idea recognized by the whole society and deeply rooted among the people. Therefore, the "peopleoriented" concept has also been widely recognized and fully used in the enterprise management. The flexible management idea and method with "people-oriented" as its essential characteristic have better adapted to the new demand of the new type of enterprise management.

The connotation and features of flexible management show that the core of flexible management mode is people-oriented. That means our ultimate purpose is to meet people's needs and realize their all-round development, respecting their rights, giving full play to their role and allowing their personalities development so as to realize their all-round development. In terms of management approach, incentives will be the main method. Subordinates could develop their own learning and work plans and goals based on their personal characters and needs. Managers will give recognition and rewards for those who perform well their study and work. This would encourage subordinates to consciously allocate their time and well complete the work, so that managers could achieve the purpose of management. [5] By applying the flexible management mode, taking employee-oriented as the new concept and incentives as a main measure, enterprises could practically implement the scientific management concept-"people-oriented" in the new period of business management.

\section{The inevitable requirements of meeting the new characteristics of contemporary employees in enterprise management}

Scanning the age structure of today's employees, those born after 1980s and 1990s have accounted for the majority. They are adults with rationality and personality independence, living independently, well dealing with interpersonal relationships and the problems in life, study and work. However, most employees in workplace are the new one-child generation, active in thinking, pursuing freedom and selfadvocating. In this network era with information explosion and rapid knowledge renewal, they receive more extensive knowledge; develop more distinct personality and stronger consciousness of rights. Facing them with various characters and publicizing individuality, the traditional rigid management emphasizing uniform and strict enforcement of orders and prohibitions could not meet the demand of current business management.

First of all, considering the distinct personalities and strong independence of employees in the new era, business management should not depend on traditional style any more. Then, in this society of materialism, fast pace and restlessness, most of the workplace freshmen are under the pressure from work and life. In the traditional rigid management mode, by virtue of strict and rigid regulations, daily attendance, special award of merit, year-end bonus, punishment for violations and other management means, the enthusiasm and creativeness of staff are suppressed. On top of suffering from the stress in their daily life and work, they also need to follow the management from their superior, complete the tasks for quantitative evaluation which are not really suitable for themselves. Applying flexible management methods, the staff could work out their own plan according to their situation and condition and allocate their time more freely, which greatly liberate the staff, remain their personalities and raise the working enthusiasm.

\section{Requirements of establishing a new relationship between business managers and employees}

For traditional management mode, managers are rulemakers, regulators of bonus and excellent staff appraisal and the person who decides how to treat employees' violation on a leading position. There is a hierarchical relationship with honorable and humble between the managers and employees. The employees are forced to follow the management of superiors without any independence and individuality, only passively accepting the orders. Therefore, the communication between the employees and the managers is unequal and insincere. Facing with freshmen's distinct characters and strong independence, this unequal relationship could not be suitable for current business management. Establishing a new relationship between employees and managers needs to be put on the agenda. Faced with the new features of freshmen, firstly, both parties should respect each other in this new employment relationship. Secondly, they should be interactive, harmonious and mutual promoting. Flexible management is a kind of equal, democratic, respecting individuality and pursuing freedom. Therefore, the need of establishing a new 
manager-subordinate relationship calls for setting up a flexible management style in companies.

In conclusion, the merging workforce in companies is complex and diverse, facing a stark reality. Companies need to release the restraint, let their employees to pursue dreams, reform the traditional rigid management and follow the trend of flexible management to benefit current employees.

\section{ThE APPROACHES of REALIZING FleXible MANAGEMENT IN BUSINESS MANAGEMENT}

\section{A. Establishment of "employee-centered" concept of flexible management}

The core of flexible management is human-based and employee-centered management. Based on the sufficient research and study on Psychology law of human behavior, flexible management develops a potential persuasiveness in a non-mandatory way, whereby the wills of collective organization could be turned into individuals' conscious behaviors. ${ }^{[6]}$ Compared with rigid management, employeecentered flexible management could meet new demands of current business management and comply with new characteristics of development of times.

Scientific and technological revolution in recent years gives birth to high and new technology industry with information industry as its representative, and also promotes the renovation of business management and business operation model. Innovation has become the crucial instrument for companies to win the market. However, the creative works and intellectual activities of knowledge-based employees could not be quantified. Therefore, their responsibility and self-consciousness are the critical factors to determine quantity and quality of their labor. In the process of management, managers should follow the employee-centered concept, fully stimulate employees' autonomy, and carry out flexible management in a reasonable and efficient way. Only through this can comprehensively and fully mobilize the employees' creativity and enthusiasm, and then good effects will be obtained.

\section{B. Implementation of management that take the incentives as a main approach, emotion communication and combination of material reward and moral encouragement as main methods}

Marxist philosophy states that internal cause plays a decisive role in an object's development. In companies' management work, the supervision and urge of managers are just external factors. For stimulating employees to discover their goals and impetus, managers encourage and inspire the employees to fully play their roles, motivate positivity, initiative and motility. Managers should induct employees to establish life goals, and long-term and short-term goals to better plan their career and discover a more suitable working approach and schedule. For one thing, managers need to carry out some incentives, keep observing employees' completion of goals and help them overcome the difficulties in realizing goals and dream. When employees counter difficulties, managers need to timely communicate with employees, encourage them, restore their decision and find approaches to overcome each difficulty. By virtue of these, managers stimulate employees to go forward towards their set goals. For other things, under the guidance of managers, employees are closer to their goals step by step and achieve the phased progress. At this time, managers should give spiritual encouragement or material reward to employees for them to build stronger confidence and stimulate more interests and motivation.

\section{Establishment of a new superior-subordinate relationship characterized by equal personality, mutual respect and harmonious interaction}

The development of business management model could be divided into three phases, which are experience management, rigid management, and flexible management. Before 20th century, entrepreneurs managed their companies based on their experience. However, since publish of Principle of Scientific Management by Taylor in 1911, the business management stepped into a new scientific management from a long phase of experience management. Based on the in-depth research and study of companies' operation organization, Taylor improved the specific operation of every factor comprehensively to raise output of production efficiently. This model has propelled the Western Industrialization. After that, rigid management has developed gradually. This mode is system-centered by virtue of regulations, discipline supervision, reward and punishment and other means. In the middle and late 20th century, the disadvantages of rigid management gradually expose. Peter-Senge proposed the importance of flexible factors in management in The Fifth Discipline, also known as the Bible of management in 20th century. He stated that in the past 30 years, some high-profile corporations in the United States established their systematic management pattern following Forrester conducive to crucial decision and the formulation and verdict of general plan. Among this process, the variety of flexible factors including leader style, attitude of communication, enterprise culture and employee morale accounts for $90 \%$. Thus, we can see that it is time to set up a new relationship of superior-subordinates which emphasize more on harmonious interaction.

\section{Improvement of managers' self-qualities}

The employees in this new era are a group with high knowledge level, strong learning ability, ambitious goals and distinct personalities. Under the flexible management, managers need to communicate more with employees, induct and help timely when employees have difficulties in their work and life. Therefore, manages should possess higher qualities, including cultural qualities, professional qualities, self-discipline and others for better management works.

\section{E. Creating enterprise cultural atmosphere characterized by positive, progressive and virtuous}

Flexible management adopts a relatively loose mode and takes a harmonious enterprise's cultural atmosphere as a base and support (Zhang Chunying, 2004). ${ }^{\text {[7] Firstly, managers }}$ need to establish correct and positive value as all employees' value orientation. By the standard of socialist core value 
system, managers should strengthen guidance of employees' view of world, life and value, induct them to establish positive, healthy views and encourage them to strive for progress. Secondly, a nice working atmosphere is of great importance in an enterprise. ${ }^{[\mathbf{8}]}$ Therefore, managers need to induct and lead employees to establish a collective atmosphere featured with mutual-help, unity \& friendly, positive and harmonious. Hence, the implementation of flexible management could be guaranteed and achieve maximum effectiveness. ${ }^{[9]}$

\section{CONCLUSION}

Contemporary employee management is faced with many new circumstances, such as the requirements of establishing free, open and new enterprises, practicing the people-oriented Scientific Outlook on Development and establishing employee-centered new enterprise, and the new characteristics of employees characterized by distinct personalities, selfpursuit and pursuing freedom, and the requirements of establishing new management relationship featured with mutual respect, understanding and benign interaction, traditional rigid management which takes regulation and rules as its core and featured with compact organization, strict enforcement of orders and prohibitions, clear reward and punishment could not adapt to the progress of current business management. Considering these, it is urgent to adopt a flexible management system, the implementation methods of which is to take employee-centered as core concept and incentives as main method, establish superior-subordinate relationship featured with equal, mutual-respect and positive interaction, improve managers' self-qualities, and build favorable enterprises cultural atmosphere.

\section{REFERENCES}

[1] Peter•Senge. The Fifth Discipline - The Art and Practice of Learning Organization. Trans. By Guo Jinlong. Shanghai: Shanghai Joint Publishing Press, 1994.

[2] Zheng Qixu. Flexible Management. Dongying: Petroleum University Publishing House, 1998.

[3] Dong Hua. Initial Study on Flexible Management. Gansu Social Science. 2001, (5)

[4] Zeng Jianxin, WanJianjun. Flexibility and Flexible Management. Journal of Zhuzhou Institute of Technology. 2004, (3)

[5] Wang Pengfei, Yuan Zheng. On the Role of Flexible Management in Business Management. Heilongjiang Foreign Economic Relations\& Trade. 2007, (2)

[6] Gong Daihua. Problems in Enterprise Flexibility Study. Journal of Industrial Engineering Management. 1999, (1)

[7] Zhang Chunying. From Rigid Management to Flexible Management--a New Path for Developing Human Resources. Techno-economics\& Management Research.2004, (2)

[8] Zhu Xiaohui, Ling Wenquan. Flexible Management in Human Resources. Commercial Research. 2005, (3)

[9] Bao Yongsheng. Study on the Role of Flexible Management in Business Management of Enterprises. Economist. 2016, (2) 